\title{
A Trajetória das Organizações de Agricultores Familiares e a Implementação de Políticas Públicas: um estudo de dois casos ${ }^{1}$
}

\author{
Alan Ferreira de Freitas ${ }^{2}$, Marco Aurélio Marques Ferreira ${ }^{3}$ e
} Alair Ferreira de Freitas ${ }^{4}$

\begin{abstract}
Resumo: Este trabalho procurou analisar como a trajetória das organizações de agricultores familiares pode afetar a implementação do Programa Nacional de Alimentação Escolar e sua execução localmente. A hipótese de trabalho é que o modo como as organizações são constituídas determina a forma como as interações com outros atores acontecem no âmbito de uma política pública, influenciando a sua execução. Para se chegar aos resultados, tomou-se como estratégia de pesquisa o estudo dos casos de Espera Feliz e de Guaraciaba, ambos localizados na Zona da Mata de Minas Gerais. O trabalho de campo revelou, conclusivamente, que as condições sociais herdadas e a racionalidade sob a qual as organizações coletivas são constituídas conformam os modos de funcionamento das mesmas e a forma de acesso a políticas públicas, podendo afetar os arranjos locais e os resultados do programa.
\end{abstract}

Palavras-chaves: políticas públicas, organizações coletivas, agricultura familiar.

Abstract: This paper sought to analyze how the trajectory of family farmers organizations can affect the implementation of the National School Food Program and then its execution locally. The working hypothesis is that the way organizations are settled determines how interactions with other actors take place within a public policy, influencing their execution. In order to obtain the results, the study of Espera Feliz and Guaraciaba cases, both located in Zona da Mata of Minas Gerais, was taken as a research strategy. The fieldwork has conclusively shown that the inherited social conditions and the rationality under which collective organizations are constituted conform the ways they operate and the way of access to public policies, which may affect the local arrangements and the results of the program.

Key-words: public policy, collective organizations, family farming.

Classificação JEL: J38.

DOI: http://dx.doi.org/10.1590/1234-56781806-94790570101

1. Data de submissão: 11 de julho de 2017. Data de aceite: 26 de fevereiro de 2018.

2. Universidade Federal de Viçosa. Viçosa-MG, Brasil. E-mail: freitasalan@yahoo.com.br

3. Universidade Federal de Viçosa. Viçosa-MG, Brasil. E-mail: marcoaurelio@ufv.br

4. Universidade Federal de Viçosa. Viçosa-MG, Brasil. E-mail: alairufv@yahoo.com.br 


\section{Introdução}

A partir das eleições presidenciais de 2002, com a vitória de Luiz Inácio Lula da Silva, os movimentos sociais e as organizações da sociedade civil inflamam as expectativas de mudança nos rumos das políticas no Brasil. No comando do Partido dos Trabalhadores (PT), Lula contemplava as reivindicações de grupos mais marginalizados, criando um contexto favorável no qual o País vivenciou a reconfiguração das políticas públicas para a agricultura familiar e a imersão de uma nova geração de públicas voltadas a essa categoria social (GRISA; SCHNEIDER, 2014).

Esta nova geração de políticas para a agricultura familiar tem seu marco institucional com a criação do Programa de Aquisição de Alimentos (PAA), em 2003, e a reformulação do Programa Nacional de Alimentação Escolar (PNAE), com a Lei no 11.947, de 2009. Esses programas foram criados (modelados) como estratégias de segurança alimentar e nutricional e combate à fome, buscando conectar produção e consumo por meio da compra institucional de alimentos da agricultura familiar.

Como especificado na Lei no 11.947 , municípios e estados brasileiros precisam investir no mínimo 30\% dos recursos recebidos do Fundo Nacional de Desenvolvimento da Educação (FNDE) na compra de alimentos das famílias de agricultores. Apenas estão isentos da compra se os fornecedores (agricultores locais) que não tiverem condições de fornecimento regular e condições sanitárias adequadas.
A Lei no 11.947 de 2009 referente ao PNAE é considerada pela literatura consultada como um grande avanço no combate à pobreza rural e à insegurança alimentar (JANUÁRIO, 2013; TRICHES, 2010, 2015; CUNHA, 2015; FROERHLICH, 2010; GRISA, 2012; SILVA; SCHMIT, 2012; ABREU, 2014; COSTA, 2013; FERNANDES, 2013).

Com a emergência desses programas, estudos mostram o fortalecimento das organizações da agricultura familiar (TRICHES, 2010; TRICHES; SCHNEIDER; SIMÕES, 2013; GASTAL et al., 2014; CUNHA, 2015; SILVA, 2015), a ampliação das relações das organizações locais da agricultura familiar com os agentes governamentais (RIBEIRO et al., 2013; TRICHES; GRISA, 2015), o aumento da produção dos agricultores familiares (CUNHA, 2015; LIBERMANN; BERTOLINI, 2015; SILVA, 2015) e a valorização dos produtos locais (TRICHES, 2010; TRICHES; SCHNEIDER， 2010; GRISA, 2012; SILVA, 2015).

No entanto, não obstante a importância para a alimentação escolar e para a agricultura familiar, o processo de compra e venda dos gêneros alimentícios no contexto desses mercados institucionais é complexo por envolver diversos tipos de ações relacionadas à potencialização da produção, processamento, distribuição e consumo de alimentos no município. Alguns estudos têm demonstrado que muitos aspectos são considerados entraves para a concretização das ações de compra dos alimentos da agricultura familiar. Dentre elas se encontra a falta de compreensão da legislação, os problemas políticos evidenciados, a falta de organização social e produtiva e a escala de produção (GASTAL et 
al., 2014; CUNHA, 2015; SILVA, 2015; MOSSMANN et al., 2017).

Parte desses entraves está no fato de as organizações sociais passarem a assumir responsabilidades na implementação do PNAE. Programas como o PAA e PNAE estimulam a formação de arranjos de implementação com interação entre atores sociais e poder público, além de apoiar a constituição de cooperativas e associações para que os agricultores familiares acessem o mercado institucional e consigam vender os produtos. Esta demanda normativa do programa tem estimulado agricultores familiares a se vincularem e/ou formalizarem organizações coletivas, como forma de atender aos requisitos do programa (SILVA; SCHMITT, 2014).

Se a implementação da compra dos produtos da agricultura familiar depende da formação de um arranjo organizacional para que eles se tornem fornecedores, nosso questionamento é como a trajetória das organizações de agricultores familiares pode afetar esses arranjos e, logo, interferir na execução do PNAE?

Segundos dados do FNDE (2016) ${ }^{5}$, no Brasil, em 2009 existiam apenas 91 empreendimentos da agricultura familiar com Declaração de Aptidão ao Pronaf (DAP), com mais de 11.674 associados. Em 2015 já são registrados 4.083 empreendimentos com a DAP jurídica e 625.608 agricultores vinculados. Os impressionantes números mostram o quanto estas políticas de compra institucional têm induzido a criação de organizações formais dos agricultores.

O incentivo à constituição de organizações formais e sua capacidade de responder às demandas da execução dos programas de compra institucional ainda são tratados de forma marginal na academia e carece de estudos para ganhar amplitude e visibilidade. Os focos de grande parte dos estudos sobre a implementação das políticas de compra institucional continuam sendo, como apontam Grisa (2012), Wagner (2015), Grisa e Schneider (2015), Mossmann et al. (2017), a avaliação de impactos, sobretudo sob uma perspectiva econômica. Desta forma, a inserção da agricultura familiar no mercado institucional não pode ser considerada apenas no contexto da geração de renda e do cumprimento dos $30 \%$ e da compra pública.

5. Informações enviadas por e-mail pelo FNDE diretamente ao pesquisador.
Considerando esse cenário, uma preocupação central deve ser, também, para além da ampliação do mercado, sobre a natureza e a sustentabilidade das organizações criadas, o que leva a pensar mais na qualidade dessas organizações do que na quantidade. A qualidade significa compreender sua capacidade de operar as responsabilidades atribuídas por meio dos programas, pois o Estado, ao incentivar as organizações formais, pode estar estimulando a criação de organizações meramente formais e desenraizadas de sua base social. Embora diversos estudos como os de Froerhlich (2010), Noronha (2013), Januário (2013), Abreu (2014), Triches e Grisa (2015), Cunha (2015), Silva (2015) e Grisa e Scnheider (2015) tenham se atentado para a importância da organização social na prática da compra institucional por meio do PNAE, as pesquisas não questionam a forma e os motivos de criação dessas organizações e a sua relação com a execução local do programa.

Estes trabalhos não consideram a influência da trajetória sócio-histórica das organizações locais no acesso aos programas e na forma como o programa é operacionalizado localmente. Com o intuito de incrementar essa discussão, este trabalho define a hipótese de que o modo como as organizações são constituídas determina a forma como as interações entre os atores acontecem no âmbito de uma política pública, influenciando a sua execução localmente. Isso quer dizer que a forma com que a organização social foi constituída pode interferir em seu desenvolvimento. Assim, considera-se que as respostas das organizações coletivas formais em termos de adaptação às oportunidades trazidas pela introdução de políticas públicas não são mecânicas nem homogêneas. Ao contrário, elas dependem de características particulares de cada entidade e do contexto de implementação.

Essas discussões nos leva a traçar o objetivo de compreender a influência da trajetória das organizações no modo como os agricultores familiares acessam as políticas públicas, especificamente o PNAE. Ao lograr tal objetivo, este trabalho pode contribuir para superar as lacunas acima mencionadas Para isso, procura-se estudar a gênese das organizações coletivas nos municípios de Espera Feliz e Guaraciaba, situados na Zona da Mata do estado de Minas Gerais, Brasil. Em ambos os municípios, o Programa Nacional de Alimentação Escolar (PNAE) figura como o mais importante programa governamental que apoia a comercialização dos produtos da agricultura familiar. 


\section{Capital social: o substrato das organizações locais}

Para compreender a formação das organizações coletivas da agricultura familiar buscou-se suporte em dois conceitos: redes sociais e capital social, os quais denotam o papel das relações sociais em processo de desenvolvimento, possibilitando compreender elementos sociopolíticos subjacentes às organizações formais e políticas públicas e a superar o caráter normativo de inúmeros estudos sobre esse tema, pautando as análises nos aspectos relacionais do fenômeno. A questão é avançar nessa discussão, contribuindo com esse campo de estudo, ao mostrar como as relações sociais podem ser o substrato sob a qual as organizações e os processos cooperativos se edificam e como o incentivo do Estado à constituição de organizações formais para o acesso a programas públicos pode estar induzindo a constituição de organizações meramente formais e nada enraizadas ao tecido social local.

Nesta direção, se faz relevante o conceito de embeddedness, ou enraizamento social, oriundo da Nova Sociologia Econômica (NSE). Concebido primeiro a partir da publicação de "A grande transformação", em 1944, por Karl Polany, o conceito foi também desenvolvido por Granovetter (2005). Essencialmente, a noção de enraizamento social pondera que as relações econômicas estão imersas em redes de relações sociais e que toda ação econômica é essencialmente uma ação social. A premissa básica é a de que a ação dos atores é socialmente situada e não pode ser explicada apenas por motivos individuais ou somente pela determinação cultural, em concepções super ou subsocializadas da ação humana.

Portanto, as redes sociais podem ser consideradas produto da trajetória associativa dos atores e de suas experiências do passado, alicerçadas em tradições e convenções. A ações e trajetórias dos atores, portanto, precisam ser socialmente contextualizadas, concebendo as redes às quais se vincularam ou vinculam $e$ como se posicionam nessas redes, pois a natureza e característica dos vínculos sociais que historicamente estabeleceram importam no acesso a diferentes recursos e em suas decisões. Assim, da mesma forma como as ações econômicas, as organizações coletivas de caráter econômico ou político devem ser socialmente situadas, sobre o risco de serem desenraizadas (RIZZA, 2006). O desenraizamento aqui representa, do ponto de vista empírico, falta de apropriação pelos sujeitos locais e de coesão do grupo social do qual emerge e, do ponto de vista analítico, de compreensões superficiais sobre a dinâmica de funcionamento da organização.

Segundo Rizza (2006), o enraizamento social estabelece uma abordagem analítica e interpretativa baseada no pressuposto teórico de que as preferências e comportamentos econômicos não podem simplesmente serem incluídos como um indicador de utilidade dos atores atomizados, mas que eles dependem de perto dos diferentes contextos sociais em que os atores atuam. Portanto, os fenômenos econômicos tendem a variar em relação aos diferentes contextos sociais e o conceito de enraizamento se torna uma ferramenta analítica útil para identificar as diferenças sociais que marcam a constituição de organizações econômicas (RIZZA, 2006).

É corroborando com essa perspectiva que uma análise da trajetória sócio-histórica das organizações econômicas locais pode contribuir para entender a formação e a configuração atual dos mercados institucionais criados a partir da implementação do PNAE. Esse processo ajuda a evidenciar as precondições sociais para a expansão das redes criadas localmente e como elas se estruturam para operar a política pública, considerando que a morfologia das redes sociais locais importam no entendimento do seu funcionamento. Long e Ploeg (1994) acreditam que, a partir de seus processos históricos e das interações resultantes dele, os grupos sociais podem criar formas de superar as barreiras que se apresentam a partir dos rumos que tomam.

A abordagem analítica das redes sociais é mobilizada aqui para desnudar os elementos levantados acima. Esse é um tipo de abordagem sociológica que busca compreender os efeitos das relações sociais sobre o comportamento individual e coletivo (MIZRUCHI, 2006), partindo do pressuposto de que o tecido social é estruturado por inúmeras redes de relacionamento (sejam vínculos pessoais ou organizacionais), que apresentam diversas naturezas. Portugal (2007) afirma que a análise das estruturas relacionais permite estudar o modo como os indivíduos são condicionados pelo tecido social que os envolve, reforçando os argumentos já apresentados anteriormente e ratificando a opção aqui realizada diante dos objetivos propostos.

Um dos importantes trabalhos que focam o papel de certas estruturas de rede é o de Burt (1992). Para 
ele, os atores que mantêm melhor desempenho são aqueles que estão vinculados a redes mais densas (e, por isso, de maior proximidade) e, ao mesmo tempo, a outras redes mais distantes, de laços mais fracos, mas que possibilitam contatos e informações não redundantes. Esse argumento dá pistas para entender que é preciso compreender a forma como as redes sociais estão estruturadas e a natureza dos vínculos criados entre os nós dessas redes. Tomando o objeto de estudo deste artigo, é possível considerar analiticamente a importância dessa análise para entender o desempenho das organizações coletivas na implementação de políticas públicas nos municípios onde atuam, uma vez que a maneira como os atores se organizam localmente e se relacionam no âmbito da política interfere no nível de autonomia, na estratégia de gestão e na centralidade de certos atores da rede.

Outra contribuição seminal aos estudos de redes foi o trabalho de Granovetter (1973) sobre o mercado de trabalho que resultou na sua teoria sobre os laços fortes e os laços fracos. O autor discorre sobre a força dos laços fracos e admite que, quando ampliamos nossos vínculos a pessoas que não são tão próximas, ampliamos a nossa possibilidade de contato. Isso acontece porque nossos conhecidos simples conhecem pessoas que são estranhas a nós. Seria possível, dessa maneira, acessar mais informações. Foi diante desta constatação que o autor, ao pesquisar o mercado de trabalho, compreendeu que as melhores chances de emprego dependiam das características estruturais das redes sociais às quais estavam inseridas. A relevância dos laços fracos está na sua capacidade de se tornar, então, elo entre redes, grupos, ou atores. Isso acontece pela ligação de grupos que não possuíam nenhum tipo de ligação direta. Assim surgem as "pontes" que fazem a ligação de um subgrupo a outro, possibilitando informações privilegiadas e acesso a recursos (políticos, sociais, econômicos etc.) (RIZZA, 2006).

Granovetter (1973), portanto, permite compreender que as pontes entre diferentes grupos sociais possibilita aos indivíduos acessar recursos e outros contatos que estariam constrangidos caso ficassem restritos ao interior de suas redes. No entanto, a falta das pontes restringe a circulação de recursos; logo, grupos deixam de acessar determinados recursos e benefícios porque não conseguiram extrapolar os limites de suas conexões mais fortes, e superar os buracos estruturais. Esta constatação permite concluir que a forma como as redes estão estruturadas condiciona o acesso dos indivíduos a diferentes recursos. No caso das políticas para a agricultura familiar, as organizações podem, então, ter informações privilegiadas se ampliarem sua conexões, expandindo os laços fracos e, assim, ampliam sua capacidade de interferirem no processo de gestão da política.

Desta forma, o contexto social local no qual as redes e as organizações formais estão inseridas é crucial para fundamentar e situar as análises. A partir deste contexto, pode-se verificar a construção dos laços, a solidificação das relações de confiança e como essas redes condicionam as organizações coletivas e das relações de mercado (RIZZA, 2006). Esses são, em geral, aspectos velados na maioria dos trabalhos de análise de políticas públicas, que se centram no desenho institucional e operativo das políticas, e acabam desconsiderando as relações sociais e como elas se estruturam no campo político.

Não podemos desvincular deste contexto a cultura e as representações, pois as ações desencadeadas no contexto social emergem também das possibilidades criadas por meio das formas como os atores representam as possibilidades da ação cooperativa. A confiança, como elemento fundante da construção de laços sociais, se perpetua, sobretudo, pela representação que os atores fazem da reputação e da trajetória do outro (GAMBETA, 1988). Maneschy e Klavdahl (2007) mostraram como as relações de confiança se tornaram propulsoras das conexões entre membros de organizações sociais e do acesso dos grupos a políticas públicas. No caso da compra pública de alimentos da agricultura familiar, Silva e Schmitt (2014), ao estudarem as organizações sociais, constataram que as redes e a confiança entre os membros eram fatores importantes a se considerar na efetivação das compras, se tornando um capital social que contribui à implementação dos programas.

Concebe-se aqui que o capital social não se concentra nos indivíduos, mas no vínculo entre eles. Esse recurso passa a ser uma característica da estrutura do grupo e, portanto, a forma como o grupo se estrutura e foi concebido importa na compreensão de suas ações. Autores de grande referência nos estudos sobre capital social, como Nan Lin (2001) e James Coleman (1990), afirmam que o capital social está ancorado em redes e relações sociais, devendo ser tratado no âmbito desses termos. 
Um aspecto importante nos estudos sobre Capital Social refere-se às condições locais para as experiências de desenvolvimento, disseminadas, sobretudo, pela obra de Robert Putnam (2002) e de outros autores que tratam das experiências bem-sucedidas dos distritos industriais da Terceira Itália. Uma série de condições e princípios favoráveis é tida como fatores cruciais do sucesso no desenvolvimento dessas regiões, produtos da ação coletiva e do senso cívico, um sentimento intenso de pertencimento à comunidade local.

Putnam (2002) traduz as redes sociais como uma espécie de capital social, entendendo as próprias redes como o relacionamento social baseado em confiança, normas socialmente construídas e valores que ajudam os indivíduos a sair de relações conflituosas e competitivas para formar laços de cooperação. Portanto, na definição de Putnam, há capital social quando as redes sociais geram cooperação e colaboração. Nesse sentido, focalizando o objeto de estudo deste trabalho, a noção de capital social contribui de maneira aplicada para entender, a partir da trajetória das organizações de agricultura familiar, se elas criam e reproduzem capital social e como esse capital interfere na dinâmica de implementação da política pública.

Para Coleman (1990), as redes constituem um recurso que os indivíduos podem mobilizar a fim de alcançar seus objetivos. Por exemplo, em um grupo em que a honestidade caracteriza as relações sociais e é institucionalizada como norma social, ela constitui uma forma de capital. A honestidade como norma leva à confiança, logo, se algum membro do grupo não agir conforme a norma sofrerá pressão dos outros membros. Assim, a rede de relações mobiliza seu capital social em função da manutenção de suas normas e criação de outras que permitam a ação direcionada.

O capital social pode ser caracterizado, segundo Woolcock (1998), de duas formas: capital social de integração e capital social de ligação. O capital social de integração é observado a partir das relações de confiança e da proximidade entre os indivíduos de um grupo. É o que Putnam (2002) definiu como capital social de vinculo (bonding). O capital social de ligação pode ser notado nas relações extragrupo, na forma como a organização ou comunidade consegue estabelecer ligações com outros grupos ao invés de se manter fechada. Putnam (2002) caracterizou capital social como ponte (bridging).
O papel dos estoques de capital social é outro elemento importante levantado por Putnam (2002). Para o autor, a existência de um contexto relacional e institucional, denominado estoque anterior de capital social, pode fornecer as bases para que as redes locais se mobilizem e criem mecanismos de superação de barreiras e em direção ao acesso a políticas públicas. Num estudo realizado com associações rurais no estado do Pará, no Brasil, Maneschy e Klavdahl (2007) apontaram que as práticas de cooperação e confiança estabelecidas antes da operacionalização dos programas públicos foi fundamental para criar lastros de solidariedade necessários ao sucesso. O capital é, desta forma, um benefício social gerado pelo estabelecimento de laços que facilita o acesso a recursos.

\section{Aspectos metodológicos}

O quadro analítico que se propõe aqui como desdobramento deste arcabouço teórico parte do que podemos denominar de dinâmicas sociais da implementação local das políticas públicas. A dinâmica social compreende a forma tomada pelo processo de implementação a partir do envolvimento de diferentes atores, os sentidos que eles atribuem a esse processo e às interações. A operacionalização dessa dinâmica social da implementação neste trabalho está vinculada especificamente à compreensão da trajetória das organizações de agricultores familiares e suas implicações para a construção de arranjos de implementação, logo, para a execução do programa estudado.

Esta é uma dimensão microanalítica. Além das interações estabelecidas no âmbito da implementação do PNAE, a literatura sinaliza a relevância de se compreender a formação histórica das redes, revelando seu contexto, em que se insere a forma de constituição das organizações. O eixo de análise dessa dimensão é, portanto, a gênese das organizações da agricultura familiar que protagonizam a venda de produtos e as interações que elas estabelecem com outros atores. As principais categorias analíticas para esse eixo foram as raízes históricas da organização social.

Para conseguir avançar no campo empírico, essa pesquisa caracteriza como descritiva e interpretativa, com abordagem qualitativa. Foi utilizado como estratégia o estudo de dois casos. Para Stake (1995), o estudo 
de casos busca ser sempre reflexivo, contrastando fatos e relacionando conceitos, e consegue ganhar amplitude e qualidade quando se atribui ao contexto metodológico mais de um caso. Desta forma, pretende-se trazer à nossa dimensão empírica dois casos singulares: Espera Feliz e Guaraciaba, municípios situados em Minas Gerais, destacando organizações formais de agricultores familiares destas localidades.

Os municípios estão localizados na Zona da Mata do estado. Esta mesorregião é caracterizada por pequenas propriedades rurais. Em Espera Feliz e Guaraciaba não é diferente. São municípios marcados por uma trajetória fortemente ligada à atividade rural. Espera Feliz é reconhecida pela importante produção de café e Guaraciaba, por uma produção mais diversificada baseada em hortaliças.

$\mathrm{O}$ município de Espera Feliz pertence à microrregião de Muriaé e sua população é de 22.856 habitantes, 14.174 situados na área urbana e 8.682, em área rural. O censo agropecuário de 2006 identificou no município $225(76 \%)$ estabelecimentos familiares e 71 (24\%) não familiares. 60,61\% das propriedades têm menos que 20 ha, ou seja, são pequenos proprietários. Há apenas 14 proprietários de estabelecimentos acima de 100 ha.

Guaraciaba posiciona-se no noroeste da Zona da Mata, na microrregião de Ponte Nova. De acordo com o Censo Demográfico de 2010, a população do município era de 10.223 habitantes, com $31,48 \%$ das pessoas residentes em área urbana e $68,52 \%$, em área rural. A população do município se reduziu, entre os Censos Demográficos de 2000 a 2010, à taxa de $-0,04 \%$ ao ano, passando de 10.263 para 10.223 habitantes.

Espera Feliz é considerado o município de minas Gerais com maior número de DAPs, sendo 2.223 e um total de 1.639 DAPs Ativas. Em Guaraciaba este número também é significativo, com total de 1.044 DAPs, sendo 794 ativas.

No que tange às organizações dos agricultores familiares, em Guaraciaba se constatou por meio de dados do Ministério do Desenvolvimento Agrário que existem cinco associações com DAP jurídica: Associação dos Resistentes a Barragens, Associação Comunitária do São Mateus e Regiões, Associação Comunitária das Comunidades do Bananal e Adjacências, Associação dos Moradores e Produtores Rurais do Patrimônio de São Sebastião (conhecida como Penha) e Associação dos Agricultores Familiares de Guaraciaba (Asfag).
Em Espera Feliz foram constatadas três organizações formais com DAP Jurídica: Associação da Agricultura Familiar da Comunidade do Angola, Associação de Agricultores Familiares do Córrego Ventania e Cooperativa da Agricultura Familiar Solidária de Espera Feliz (Coofeliz). Optou-se por tomar como caso central de análises a Coofeliz, por ser a organização econômica mais antiga a operar a venda para a alimentação escolar e por possuir uma trajetória de relação com outros tipos de organizações da agricultura familiar, como o sindicato e a cooperativa de crédito. Guararaciaba e Espera Feliz foram escolhidos por se situarem na Zona da Mata, possuírem grande presença de organizações da agricultura familiar e pela facilidade de acesso que os pesquisadores tinham aos informantes da pesquisa pela realização de projeto de extensão em ambos municípios.

Os dados foram coletados por meio de entrevistas semiestruturadas aplicadas durante os meses de março a setembro de 2016, cuja amostra foi definida pelos critérios de acessibilidade e saturação (GIL, 2011). As entrevistas foram realizadas enquanto houve necessidade de se obter as informações para subsidiar a análise e preencher as lacunas do problema de pesquisa. A seleção dos entrevistados foi pautada nas indicações feitas por outros entrevistados, pela disponibilidade deles e pelas condições logísticas de realização da pesquisa. Foram realizadas 26 (vinte e seis) entrevistas, sendo 14 no município de Guaraciaba e 12 em Espera Feliz. Os informantes foram divididos em três categorias: agricultores familiares (vinculados a organizações formais), poder público local e parceiros. Para citar os depoimentos ao longo do texto utilizou-se a categoria do informante e um número que caracteriza a ordem das entrevistas, por exemplo: agricultor familiar 01, agricultor familiar 02 etc., e o município a que pertence.

Como técnica de organização e análise dos dados, optou-se pela "análise de conteúdo" que, de acordo com Bardin (2011), foi operada por meio de três etapas subsequentes: i) a pré-análise, ii) a exploração do material, e iii) o tratamento dos resultados, a inferência e a interpretação. Na primeira, foi realizada a transcrição das entrevistas e realizada uma leitura geral para reconhecimento das informações coletadas. Nessa primeira exploração, os depoimentos e demais dados foram separados para compor as análises e agrupados por município e de acordo com duas categorias: gênese das organizações e implicações da forma de constituição. 


\section{Constatações empíricas}

A partir de incursões empíricas nos dois municípios, realizando conversas informais com lideranças das organizações estudadas, alguns questionamentos surgiram e guiaram os próximos passos da pesquisa. A constatação mais contundente que norteou a pesquisa é que, no município de Guaraciaba, as associações tiveram sua criação vinculada a um processo instrumental de imposição por parte do poder público e agentes externos para que se formalizassem. Em Espera Feliz, uma série de organizações coletivas vinculadas ao Sindicato dos Trabalhadores Rurais surge em função das mobilizações dos próprios agricultores, de suas necessidades e das oportunidades oriundas das novas políticas para a agricultura familiar.

\subsection{As organizações coletivas e a rede de agricultores familiares em Espera Feliz}

Com a pesquisa de campo, foi constatado que, no município de Espera Feliz, existe uma rede interorganizacional composta por organizações coletivas de agricultores familiares. Tal rede emergiu sobre uma rede social constituída, a princípio, pelo Sindicato dos Trabalhos Rurais (STR) de Espera Feliz. O sindicato tem sido a principal referência dos agricultores familiares dessa rede.

$\mathrm{O}$ depoimento a seguir fortalece essa afirmativa e traz a expressão do surgimento das organizações locais:

"Aqui, primeiro a gente teve o trabalho forte que o sindicato fez deste a CEBS [Comunidades Eclesiais de Base]. Muita gente se engajou e ajudou. Depois a gente viu que não podia ser só trabalho político. Veio um monte de política nova para os agricultores familiares e tivemos que aproveitar. O Sindicato ajudou e ajuda até hoje. Foi aparecendo a oportunidade de ter alguma coisa e a gente constituiu associação, depois teve a demanda pelo crédito. A gente tem a Cresol, e aí, com a oportunidade de comercializar, tivemos que ter a Coofeliz. E assim fomos criando essas organizações, cada uma de uma vez" (Agricultor Familiar 02 de Espera Feliz).

Pelo que foi observado, as organizações constituídas nesse tecido social surgiram a partir das opor- tunidades criadas pelas políticas públicas aliadas às necessidades dos agricultores, mas principalmente fundada na dinâmica de relação já instaurada pelo sindicado.

Essas transformações, segundo Sabourin (2006), estão relacionadas, sobretudo, às mudanças nos ambientes institucionais, principalmente ligadas às políticas públicas e que incidem diretamente nas práticas econômicas e organizativas dos agricultores. Para esse autor, as dinâmicas locais são forçadas a sofrer alterações à medida que estão em jogo novas políticas e alternativas aos problemas sociais e econômicos enfrentados por esse segmento.

O relato de Dirigente da Coofeliz sublinha a dinâmica de criação das organizações e a existência da rede e as concepções simbólicas dos elementos de ligação entre os agricultores. Discorrendo sobre "o que nos une", a informante relata que:

"na verdade, se eu for falar da cooperativa de produção, eu tenho que falar que aqui não é só a Coofeliz, tem um conjunto de organizações que andam juntas e uma não seria nada sem a outra. Por exemplo, primeiro surgiu o sindicato, do sindicato veio a associação intermunicipal de agricultura familiar, veio o grupo de mulheres, aí veio cooperativa de crédito, veio cooperativa de produção, tem o trabalho com os jovens, com a homeopatia, então, assim, é um conjunto de ações que funcionam no coletivo, então, pra nós, quando você discute comercialização, por exemplo, você discute crédito, discute acesso à terra, tudo isso está no coletivo" (Dirigente Coofeliz, Epera Feliz).

O depoimento caracteriza o surgimento de um universo organizacional a partir de uma rede pessoal que serve como base de origem para a ação coletiva. Ao mencionar que "não é só a Coofeliz" e que as organizações "andam juntas", a informante pondera a existência de uma base comum de atuação, de unicidade de agenda política, embora em organizações distintas. Em todas as organizações citadas no depoimento, a base social é a mesma: agricultores familiares vinculados ao STR; caracterizando um elemento comum de identidade que reforça a proximidade social e engajamento político.

O STR de Espera Feliz tem sua atuação política vinculada às lutas em defesa dos trabalhadores e 
trabalhadoras rurais. Foi estruturado historicamente em torno da mobilização de agricultores familiares locais que buscavam seus direitos sociais. O STR também atua diretamente no incentivo dos sindicalizados à participação nas organizações coletivas locais, como forma de fortalecer o movimento político e econômico da agricultura familiar.

Outras organizações citadas no depoimento acima que são importantes para as dinâmicas locais são a Asimaf, o trabalho com jovens e o grupo de mulheres ${ }^{6}$. Primeiro surgiu a Associação dos Pequenos Produtores de Espera Feliz e Caiana (Apefec), no início da década de 1990, a qual se transformou em Associação Intermunicipal da Agricultura Familiar (Asimaf) em 1995. Um dos informantes da pesquisa relata que:

"A Asimaf vira Asimaf quando o associativismo entra em pauta no sindicato. Agente passou a ver que o termo agricultura familiar tinha pegado e tava surgindo muita oportunidade, aí foi necessário passar por algumas mudanças para tentar acessar algum recurso e continuar com a possibilidade de vender. $\mathrm{O}$ CTA ajudou muito nessa empreitada. Sem ele não sei como a gente teria seguido em frente. Os outros sindicatos também estavam sempre juntos e a gente via que há uma articulação nacional para fortalecer o associativismo" (Agricultor Familiar 01, Espera Feliz).

O depoimento reforça que as transformações nas políticas para a agricultura familiar foram propulsoras das mudanças na forma de organização social. Indica também que o grupo de agricultores mantinha-se alinhado com as mudanças políticas no País. Aparece, nesse cenário, o Centro de Tecnologias Alternativas da

6. No âmbito das mudanças, com incentivo do sindicato, é criada a Pastoral da Juventude Rural (PJR) que possui importante atuação junto aos jovens, com o intuído de incentivo ao engajamento nas diversas organizações locais. Esse trabalho também culminou na denominada "Escolinha Sindical", que promove a inserção dos jovens nos processos de formação política baseados nas concepções do próprio sindicato. O Grupo de Mulheres surge atrelado aos trabalhos do sindicato, mas se origina na crescente demanda de apoio às atividades de geração de renda com base na mão de obra feminina. As políticas afirmativas especificamente voltadas para mulheres rurais foram provenientes de outra demanda que fez emergir esse grupo, consolidando-o como organização integrante do arranjo local.
Zona da Mata de Minas Gerais (CTA-ZM), que atuou e atua como mediador assessorando as práticas produtivas e organizativas dos agricultores e a articulação com outros sindicatos. De acordo com entrevista feita com o técnico do CTA-ZM, o caráter da parceria é "promover a produção agroecológica, mas gerar autonomia. É uma assessoria baseada no que eles acham importante, sem ter imposição".

Em 2004, a partir de uma política de incentivo ao cooperativismo de crédito, mobilizada pela Agência de Desenvolvimento Solidário (ADS), vinculada à Central Única de Trabalhadores (CUT), e frente às dificuldades de acesso ao crédito, foi constituída a Ecosol Tombos (Cooperativa de crédito Solidário) com um posto de atendimento em Espera Feliz. Um grupo de agricultores vinculados ao STR assumiu a organização e constituição da Ecosol Espera Feliz. Em 2012, a Ecosol se transforma em Cresol (Cooperativa de Crédito com interação solidária) ao se filiar ao sistema de cooperativas de crédito do Sul do País. A Cresol, em Espera Feliz, em sua origem, teve total vinculação ao STR, ao ponto de existir em seu estatuto a obrigatoriedade de que os cooperados da cooperativa de crédito tivessem comprovadamente vínculo com o STR. Atualmente, essa normativa não existe, mas ainda boa parte dos agricultores vinculados à Cresol é de agricultores sindicalizados.

A Cooperativa de Produção de Espera Feliz (Coofeliz) tem sua formalização em 2006 ligada a esse mesmo movimento, desencadeado pelas demandas dos agricultores e pelas transformações nas políticas de desenvolvimento rural. Se para a Cresol a necessidade de acesso ao crédito foi o motor de sua emergência, para a Coofeliz a necessidade de comercialização dos produtos locais é que ocasionou sua origem. Uma mudança no código civil em 2002 transformou as associações como a Asimaf em "associação sem fim econômico", colocando entraves à comercialização e à geração de nota fiscal. Outro motivador à constituição da Coofeliz foi a possibilidade de vender produtos via PAA. De acordo com o Agricultor familiar 04 de Espera Feliz:

"foi criada [Coofeliz] porque apareceu o PAA e porque tinha aquele negócio de associação não poder mais comercializar. Já existia a discussão de cooperativismo e chegou uma hora que não deu mais pra fugir, tivemos que trans- 
formar a Asimaf na Coofeliz" (Agricultor familiar 04 de Espera Feliz).

A Coofeliz participa da entrega de gêneros alimentícios de seus cooperados para as escolas públicas do município, por meio do PNAE. Esse programa exige um esforço coletivo para organizar a produção e a comercialização. O depoimento de Dirigente da Coofeliz reforça essas constatações e agregam argumentos que ajudam a compreender o processo de origem da cooperativa.

"A Coofeliz na verdade é o que era nossa Asimaf. Que fazia essa política que a cooperativa faz hoje, que é a comercialização. Aí foi visto que associação não tem o vínculo nem perfil de comércio, então a cooperativa surgiu através dessa ideia de trabalhar o comércio dos agricultores independente da política pública. Depois veio as políticas públicas e acabou que a cooperativa entrou, mas a princípio surgiu com a preocupação de comercialização dos produtos dos agricultores independente de políticas públicas. Tinha um movimento nacional que surgia com a Unicafes. Cooperativas que eram exclusivamente de agricultores e a gente queria se inserir" (Dirigente Coofeliz, Espera Feliz).

Segundo registros do diário de campo, "quando a cooperativa foi constituída, havia apenas 20 cooperados fundadores que já se conheciam e foram parceiros nos movimentos religiosos". O baixo número de cooperados, no início, se deu por conta da pouca credibilidade que a cooperativa possuía e ao desconhecimento sobre a função da organização. À medida que foi se consolidando a forma de funcionamento e estruturando o processo comercial via cooperativa, mais adeptos foram ingressando. Quando as políticas de compra institucional de alimentos chegaram à Espera Feliz, o quadro social teve um crescimento considerável, sendo que em 2015 havia 96 cooperados ativos. Importante ressaltar que os cooperados já estavam cientes de um movimento nacional de representação das cooperativas de agricultura familiar: a União Nacional das Cooperativas de Economia Solidária e Agricultura Familiar (Unicafes).

É importante salientar que todas essas alterações no quadro organizacional de Espera Feliz tive- ram constante influência de organizações externas ao município e ao sindicato, indicando a ampliação dos laços fracos apontado por Granovetter (1973). A principal organização que exerce influência é o CTA-ZM, que acompanha as organizações locais e realiza importante trabalho de incentivo aos sistemas de produção agroecológicos.

A partir de recorrentes depoimentos sobre a origem das organizações que citavam o papel do STR, as CEBs e o "movimento religioso", fez-se necessário resgatar alguns elementos relativos a essa questão para complementar as análises. Foi um esforço de desvendar a trajetória sócio-histórica das relações sociais, ou seja, a origem das redes de agricultores familiares que criou o tecido social em que estas organizações surgiram e se enraizaram. A emergência das organizações em Espera Feliz ocorre ligado às tramas sociais (redes) locais, dando dinamicidade ao processo organizativo. A forma como a organização ocorre e como atuam as organizações coletivas é direcionada e influenciada por esse enraizamento nas dinâmicas e redes locais, corroborando a natureza social dos fenômenos organizativos e econômicos abordados por Rizza (2006).

\subsection{As raízes históricas das redes interorganizacionais em Espera Feliz}

Em Espera Feliz, a atuação da igreja católica na animação de experiências religiosas e políticas de cunho comunitário, historicamente alicerçadas na agricultura familiar, foram fundamentais para solidificar valores e processos de cooperação que culminaram na rede interorganizacional supracitada. Tais experiências foram resultantes das atividades desenvolvidas por meio das Comunidades Eclesiais de Base (CEBs). As CEBs, como se analisa posteriormente, introduziram elementos culturais e simbólicos que cimentaram a confiança e a solidariedade nas conexões entre os agricultores locais (FREITAS; FREITAS, 2013).

De acordo com Petrini (1984), CEBs são grupos de cristãos que se reuniam regularmente na casa das famílias rurais ou nos centros comunitários, a fim de discutirem a bíblia e debaterem sobre as questões sociais, econômicas e políticas que os afligia. A ideia de comunidade posta pela CEBs vinha de sua organização por grupos formados por indivíduos de uma mesma identificação geográfica: as comunidades rurais. O elemento "comunidade" e o debate em torno das 
"relações fraternas" reforçavam, entre os participantes [agricultores familiares], a proximidade social e a solidariedade.

No trabalho desenvolvido pelas CEBs, era presente a crítica da realidade social vivenciada ao reforçar os problemas econômicos e sociais causados pela desigualdade e pela exploração dos trabalhos dos menos favorecidos. A fé cristã, baseada em valores éticos e de solidariedade, era outro pilar de sustentação da atuação das CEBs (CINTRÃO, 1996). Para Silva (2010), a atuação das CEBs em Espera Feliz foi marcante ao desencadear uma série de mudanças na estrutura social e nas relações de poder, constituindo novas relações políticas e engendrando processos de organização.

A atuação das CEBs, como descrito, marcadamente tenta romper com a grande correlação de forças que existia com o Estado e entre grandes fazendeiros e pequenos agricultores, promovendo mais autonomia $\mathrm{e}$ consciência crítica. Como afirma o depoimento de um agricultor entrevistado em Espera Feliz:

"quando tinha o trabalho da CEBs a gente se reunia para discutir a bíblia, mas também fala de tudo da vida. A gente saía despertado para olhar diferente pras coisas. E acabava que eu e os outros que sempre estavam comigo queríamos mudar tudo aquilo que a gente passava" (Agricultor Familiar 04, Espera Feliz).

Os depoimentos indicam que o trabalho da igreja católica era de fomentar a transformação social e incentivar o espírito de comunidade. Para Houtzager (2004), a igreja exercia o papel de "incubador institucional", o que propiciou o surgimento de um novo sindicalismo rural, combativo e sustentado pelas lutas políticas. Nesse processo, Campos e Mendes (2011) acrescentam que a referência à comunidade fez emergir relações de confiança, alicerçadas nas experiências de fé e nas interações sociais.

O trabalho pastoral da igreja com as CEBs foi reforçado com o início do Movimento da Boa Nova (Mobon), que surge no final da década de 1970, promovendo encontros regionais que reuniam diferentes representantes de cada CEB. De acordo com Comenford (2003), com o Mobon começou-se a discutir formas de intervenção na realidade, de modo a promover mudanças sociais e políticas. As associações, os sindicatos e os partidos políticos eram formas de organização incentivadas como meio, sobretudo, de resis- tência ao êxodo rural e à exploração dos agricultores mais pobres pelos fazendeiros.

Esse movimento, segundo Silva (2010), deu origem a 15 sindicatos de trabalhadores_rurais na microrregião de Muriaé, que engloba Espera Feliz, evidenciando essa região como um território de forte densidade política. Os primeiros presidentes dos sindicatos eram oriundos do trabalho das CEBs e haviam acompanhado o Mobon. As lideranças comunitárias começavam a surgir e, devido aos trabalhos políticos, as redes começavam a se expandir, assim como relata o diretor do STR:

“Hoje nós estamos na cooperativa. Mas eu e fulano ${ }^{7}$, por exemplo, estivemos juntos desde as CEBs. Vimos tudo isso que se tem hoje crescer. Na época, o sindicato era muito atuante. Depois que constituiu o sindicado, a gente passou a ter mais contato com as lideranças de outros municípios e a participar de um monte de evento. Tudo que aparecia, que era luta e que era coisa boa a gente ficava sabendo. Acabou que até hoje todo mundo que era dos sindicatos aqui da região se conhece. A cooperativa mesmo foi incentivo do sindicato. Pode ver que aqui na região tem outras parecidas que nasceram do movimento para resolver nossos problemas econômicos" (Parceiro, Espera Feliz).

A partir dos relatos é possível compreender que as associações e os sindicatos emergem das contestações sociais e das lutas políticas. A cooperativa de produção, uma pessoa jurídica com finalidade econômica, está atrelada às estratégias econômicas e às necessidades da agricultura familiar, num cenário de acesso a mercados e expansão da produção. Segundo relatos coletados em campo pode-se constatar que, conforme as CEBs perdiam sua referência, as organizações se destacavam e ressignificavam o movimento da agricultura familiar, dando prioridade a questões econômicas como o acesso a mercados e a políticas públicas.

Desta forma, o processo de formação provocado pelas CEBs foi modelando novas relações, construindo arranjos organizacionais e edificando instituições que pudessem dar conta das novas expressões (econômi-

7. Optou-se por não citar o nome para guardar sigilo sobre a informação. 
cas) da agricultura familiar na região. Segundo relatos de representante da cooperativa de crédito Cresol:

"se for pensar como é que surgiram essas organizações aqui no município, primeiro que antes das cooperativas vieram as CEBs. Depois das CEBs veio o STR e depois vieram as organizações. Foram as CEBs que ajudaram o povo daqui a buscar alternativas. Aí vieram as necessidades e, com elas, as organizações. A coragem e a vontade todo mundo já tinha. As questões do trabalho rural tinham o sindicato, do crédito a Ecosol e na comercialização a Coofeliz" (Dirigente Cresol, Espera Feliz).

Esse depoimento revela a constatação encontrada em Silva (2010), que observa que, nos municípios onde houve forte atuação das CEBs e dos STRs, surgiram várias organizações vinculadas à agricultura familiar para suprir demandas que não cabiam mais aos sindicatos. Para esse autor, as demandas eram, sobretudo, de acesso a políticas públicas e mercados. Essas organizações são, então, fruto da convergência direta de várias redes sociais que surgem pelos contatos estabelecidos e pelas informações que circulam nessas redes. As regras do jogo, nesse caso, foram construídas historicamente, no processo social de interação, balizada na experiência de fé e na política.

Junto ao movimento pastoral, ainda na década de 1980, surge outro ator importante na construção das redes sociais de agricultores familiares em Espera Feliz: o CTA. Esta organização se inseriu junto aos agricultores vinculados ao STR e às CEBs, num movimento em prol de um desenvolvimento alternativo, balizado por uma proposta de tecnologias alternativas, sobretudo na produção. O CTA introduz um modelo de agricultura que valoriza o componente ambiental, e esse elemento é incorporado à pauta do sindicato e ganha aderência entre os agricultores familiares (SILVA; AMORIM JUNIOR, 2013).

O percurso caminhado pelo CTA no movimento da agricultura familiar em Espera Feliz consolidou um modelo de produção baseado na agroecologia, sem o uso de agrotóxicos, e institucionalizou um canal de diálogo entre os agricultores. Com o viés de atuação política do sindicato e com a introdução da agroecologia pelo CTA, os agricultores conseguiram expandir suas redes de contato para além dos limites regionais. Nessa trajetória, várias lideranças locais, bem como os agricultores, puderam participar de reuniões e outros eventos por meio das organizações estaduais e nacionais dos sindicatos e de outros eventos mobilizados e catalisados pelo CTA, como a Articulação Nacional de Agroecologia (ANA) e comercializar seus produtos em Belo Horizonte e no Rio de Janeiro.

\subsection{A indução da formação de organizações locais em Guaraciaba}

O caso das organizações coletivas em Guaraciaba tem diferenças significativas em relação à Espera Feliz, principalmente no que tange à trajetória sócio-histórica que desemboca na constituição das associações rurais e na instrumentalidade do processo. Uma especificidade local que chamou a atenção para o caso é o fato de Guaraciaba, um município predominantemente rural (68\% da população), com cerca de 10.200 habitantes $^{8}$, ter nove associações de agricultores familiares constituídas e cinco com DAP jurídica ativa. Basicamente, cada associação cumpre a mesma função.

As associações em Guaraciaba recebem o nome das comunidades rurais em que se situam. Isso quer dizer que a lógica de criação das associações existentes no município teve como referência a localização geográfica, ou seja, a comunidade, uma região no meio rural que tem maior densidade populacional. A proximidade social apareceu como fator preponderante para a criação das organizações.

Apesar de a existência de nove associações denotar que possam haver importantes relações de cooperação e uma forte rede interorganizacional, a pesquisa revelou o contrário para o caso de Guaraciaba. O que se revela é que a criação das nove associações ocorreu por indução de algum agente público externo à comunidade rural e à rede dos agricultores. Os principais incentivadores da constituição de associações rurais foram a administração pública local, por intermédio de alguma secretaria municipal, e a Empresa Mineira de Assistência Técnica e Extensão Rural (Emater). Bem-intencionados, os agentes externos que incentivam a constituição de associações possuem como ideia-força que a cooperação como forma de organização social é a melhor solução para os problemas enfrentados pelos agricultores.

8. Dados retirados do Censo Demográfico de 2010. 
O agricultor familiar 04 de Guaraciaba salienta que as associações "[...] foram surgindo, muito com o incentivo da prefeitura na época da compra do PAA da Conab, algumas associações foram criadas para participar de Conab, sem nem mesmo saber o que era". Esse depoimento reforça que o motivo de criação de parte das associações esteve vinculado estritamente à possibilidade de acesso a programas públicos como o Programa de Aquisição de Alimentos (PAA).

Ao questionar os agricultores sobre como as associações foram criadas, as entrevistas revelaram que a criação sempre ocorria por meio da mobilização de lideranças, e não das pessoas da comunidade. Esse formato de criação das associações e a consequente forma de funcionamento levaram à personalização da organização ou à interpretação de que a associação é o próprio programa público para o qual ela foi induzida a operar.

Visto que uma liderança local é que responde pela associação e historicamente se construiu como a referência, todo tipo de informação e ação referentes ou de interesse ecoam via liderança. Cria-se a passividade dos membros, reproduzindo a forma de criação. $\mathrm{O}$ depoimento do agricultor familiar 01, participante da associação da Penha, quando questionado se faz parte de uma associação, exemplifica a constatação acima ao afirmar que: "eu faço parte dessa associação de Guaraciaba, né? Da prefeitura. E também da associação da Penha, que é da Conab". Para o entrevistado, a Asfag é uma associação pertencente à prefeitura e a da Penha ao PAA, programa da Companhia Nacional de Abastecimento (Conab). Quando a criação da organização não se vincula às dinâmicas sociais locais, o sentimento de pertencimento em relação à organização fica comprometido, assimilando ainda mais o comportamento passivo em relação à atuação da organização. Exceto informantes que eram dirigentes, todos os outros agricultores entrevistados e aqueles que se realizaram conversas informais disseram desconhecer o que a associação faz para além do acesso ao PAA e Pnae. Apenas um agricultor relatou que a Associação de São Mateus faz compra conjunta.

No contexto apresentado, quando um desafio referente à atuação da associação aparece em cena, os agricultores, passivos em relação à organização, esperam alternativas e formas de resolução a partir do poder público local. É o que confirma a Secretária de Meio Ambiente e Produção Rural (SMAPR) de Guaraciaba: "é muito complicado ver os produtores tomando iniciativa, é a prefeitura que tem que correr atrás. Se precisam de alguma coisa eles recorrem aqui mesmo, ou comigo ou com o pessoal da Emater. Mas a gente está sempre aberto. Eles precisam" (Poder público 01, Guaraciaba). Quando questionada sobre as relações históricas de cooperação em Guraciaba, a representante do poder público 01 argumentou que o município não possui um histórico de cooperação. Para a entrevistada, em Guaraciaba, os agricultores familiares:

"são mais individualistas mesmo, entendeu? Cada um buscando o seu e, tipo assim, e contrata alguém. Sempre tem alguém trabalhando, a gente paga pelo dia trabalhado, mas essa troca de, como que falava antigamente, troca de praça, não; isso não existe não. Eles até têm boa relação entre eles. Mas daí a fazer alguma coisa junto é difícil, ainda mais se tiver que assumir alguma responsabilidade e depender da confiança do resto do grupo" (Poder público local 01, Guaraciaba).

Quando se questiona "o que os une" a resposta não mostra um elemento identitário e o pertencimento local, mas revela um objetivo instrumental que levou à constituição das associações. Os agricultores relataram nas entrevistas não haver relação entre as associações, denotando a não existência de uma rede intraorganizacional e um nítido desconhecimento em relação ao funcionamento de outras associações.

Sobre a forma de constituição e suas implicações, o depoimento a seguir apresenta elementos importantes às análises feitas até aqui:

"A associação? Ela surgiu porque tinha um trator e só podia doar o trator para a associação. Aí a gente correu pra constituir. Foi bom, mas ninguém se interessou por mais nada. Reunião, então, é complicado de dar gente. Ninguém quer participar. Só se tiver alguma coisa de recurso em pauta. Eu caí na burrice de ser presidente, mas não quero isso pra minha vida mais não" (Ex-presidente da Asfag).

Esses depoimentos revelam que, além do interesse em acessar benefícios vindos de políticas públicas, existem associações que foram induzidas por algum político intencionado em transformar a comunidade em 
seu reduto eleitoral. Nesse caso, a associação foi constituída para conseguir viabilizar um projeto para criação de oportunidades de lazer ou para receber um trator. Outra constatação que precisa ser reforçada é a vinculação quase que exclusiva das associações com o PAA e o PNAE. Como a comercialização dos produtos da agricultura familiar é um gargalo importante da atividade agrícola, esses programas aparecem como importantes catalisadores da oportunidade de inserção dos produtos no mercado. Para a entrevistada do poder público 01, as associações atualmente "são baseadas exclusivamente no PAA e PNAE, só em programa do governo". Apenas uma das associações, a do Córrego, é que não trabalha com PNAE e PAA, embora muitos de seus associados entreguem alimentos para esses programas via ASFAG.

Apenas o entrevistado agricultor familiar 04 apontou a necessidade de expandir as associações para além dos programas públicos:

"os produtores acham que a associação tem que viver em função do PAA e do PNAE. Na verdade, não é bem assim. Você tem que desmembrar, você tem que levar pro mercado, você tem que levar, vender de porta em porta, você tem que procurar uma feira, você não tem que ficar agarrado no PAA. E lá, infelizmente, os sócios pensam nesse sentido, de ser do PAA. 'ah, num tem PAA'; 'que dia que vai ter dinheiro da Conab?', né? E, na verdade, tipo assim, eu acho que eu me sobressaí mais do que alguns outros produtores, pelo fato, eu como outros também, né? Pelo fato de a gente não pensar só no PAA, porque o PAA não resolve o problema das famílias, porque vem verba esse ano eu tenho PAA pra mim trabalhar, mas ano que vem eu posso não ter, eu tenho o PNAE que é uma quantia menor" (agricultor familiar 04, Guaraciaba).

Esse depoimento mostra a preocupação recorrente do agricultor em relação à dependência dos programas públicos. Além desse problema, é notável que surjam outros elementos desafiadores e de complexidade considerável aos agricultores. Ao se constituir uma associação, inicia-se uma pessoa jurídica e, com ela, vêm as burocracias e a necessidade de gestão.

Em Guaraciaba, fruto desse processo de indução das associações para acessar os recursos públicos, a operacionalização da compra de alimentos, via PAA e PNAE, é centralizada na prefeitura e na Emater. As associações são periféricas nesse processo, pela passividade que assumiram ao longo de sua trajetória. Para que a compra institucional aconteça, a prefeitura disponibiliza uma funcionária especificamente para o trabalho com a gestão do PAA e do PNAE e que também fica responsável por toda burocracia da Asfag, como se fosse a secretária e gestora da associação. Pelo fato de haver grande dependência das associações em relação à prefeitura e à Emater, essa funcionária se tornou a principal referência dos agricultores e das associações. Toda e qualquer dúvida que os agricultores possuem sobre o Pnae e sobre a associação recorrem à ela. Apenas a associação da Penha foi apontada como detentora de uma autonomia relativa, embora também usufrua, mesmo que de forma parcial, dos trabalhos dessa funcionária.

De acordo com a entrevistada do Poder Público 01:

"na verdade, essa ajuda da prefeitura é muito boa, porque faz as coisas andarem para a associação, mas, ao mesmo tempo, eles acomodam. Do mesmo jeito que eu acho que ajuda, eles não avançam em querer aprender. $\mathrm{Na}$ verdade, se não tivesse a prefeitura, a coisa não acontecia, eles não conseguiam nem vender pra escola".

O trabalho realizado pela funcionária da prefeitura na gestão do programa tem sido fundamental para manter a compra pública funcionando. Com uma posição periférica no processo de operacionalização dos programas de compra institucional de alimentos em Guaraciaba, os agricultores não conseguiram expandir seus contatos para fora do município ou com outros agentes estratégicos. Um ponto é que o STR de Guaraciaba só realiza trabalhos burocráticos ligados à previdência dos trabalhadores rurais e sequer foi citado nos depoimentos coletados. Sem organizações políticas de referência e atuantes de acordo com as demandas dos agricultores, os grupos comunitários que deram origem às associações vincularam um objetivo meramente instrumental a esse processo e não descobriram um elemento que os una para além de acessar políticas públicas ou outro benefício estatal.

As organizações não surgiram enraizadas nas redes e nas dinâmicas dos agricultores familiares, mas de acordo com a mobilização realizada pelos agentes 
externos que induzem a constituição. Isso condiciona o modo como as organizações agem e desvincula a organização como entidade social (organização como substantivo) de outros processos de organização (organização como verbo). Essa dinâmica pode induzir a emergência de organizações formais, mas não necessariamente há indução do capital social. É importante retomar Lin (1999), ao considerar que o acesso e o uso dos recursos sociais enraizados nas redes sociais dependem parcialmente das posições na estrutura social e na existência de relações com laços fracos. Neste caso de Guaraciaba, a dependência que demonstram possuir do poder público local os empurra a estar numa posição periférica em relação à operacionalização de políticas públicas como o PNAE; e sua dificuldade em expandir os laços fracos também gera prejuízos à esse processo.

\section{A trajetória das organizações e as políticas públicas}

De maneira geral, existem três elementos presentes no processo histórico evidenciados até agora que merecem destaque para salientar diferenças nos processos organizativos de Espera Feliz que o distingue de Guaraciaba, os quais guardam importante relação com o dinamismo da implementação das políticas públicas constatado em campo. Em primeiro lugar (i), o movimento religioso, que fundou a noção de comunidade e institucionalizou a reciprocidade e a solidariedade como valores essenciais. A (ii) agroecologia, que se conformou como instrumento constituinte da identidade do grupo e serviu como meio de expansão das conexões sociais. E por fim, (iii) o caráter da assistência técnica que, em Espera Feliz, assumiu uma abordagem construtivista ampliando a autonomia dos agricultores e contribuindo com a expansão de suas redes. Estes elementos contribuíram para definir normas e valores enraizados no tecido social que fazem parte das representações sociais dos agricultores, o que torna possível que atores coordenem suas ações no sentido de atingir determinados fins.

Na experiência de Espera Feliz, a formação de lideranças e grupos diretamente ligados às CEBs e ao Mobon resultou em movimentos comunitários mais fortes e atuantes, desenvolvendo habilidades de articulação e intervenção na realidade local. O trabalho gradual de formação política promovida pela igreja alicerçou a construção do capital social. Putnam (1996) argumenta que esta espécie de dotação social é histórica e culturalmente construída, sendo definida por elementos das organizações, como envolvimentos em redes coesas, existência de confiança entre os atores e de normas comuns de comportamento, que facilitam a ação e a cooperação entre elas para benefício mútuo. $\mathrm{O}$ autor afirma que um "estoque" considerável de capital social facilita a ação coletiva e fortalece a identidade do grupo e sua intervenção em outras esferas de atuação.

A ampliação dos laços e a conexão com atores fora da rede de organizações da agricultura familiar local é outro fator importante às análises. Nos depoimentos dos informantes da agricultura familiar de Espera Feliz aparecem diversas organizações que de alguma forma se conectam com a experiência local, como: CUT, CTA-ZM, Cresol, Unicfes, Sindicatos. A ampliação das redes sociais, dos laços fracos, fez com que o grupo de agricultores inserido no movimento religioso (da CEBs), no movimento político (do STR) e nos processos de desenvolvimento alternativos (do CTA) instaurasse uma dinâmica social própria balizada pelas relações de cooperação.

Como mencionado nos relatos colhidos em campo, a participação nesses espaços internos e externos ao município conferiu inovação aos processos técnicos e tecnológicos na agricultura familiar. As informações sobre políticas, programas e outras oportunidades eram acessadas mais facilmente. Mais tarde, todo esse processo de formação e interação culmina na introdução de agricultores familiares desse grupo nas principais organizações citadas e em cargos políticos. ${ }^{9}$

As relações de confiança e solidariedade construídas nessa trajetória se tornaram valores essenciais na construção das redes e das organizações locais. Segundo Fukuyama (1996), a confiança é uma virtude social construída na interação, pois, sem ela, não há cooperação. Esse capital social, possibilitado pelo trabalho pedagógico das CEBs, constituiu uma estrutura social capaz de conduzir as mobilizações sociais, a atuação dos movimentos políticos da agricultura familiar e as emergências das organizações coletivas locais. Dessa forma, pode-se dizer que o trabalho pastoral, o movi-

9. Cargos políticos referem-se à eleição de um vereador oriundo do sindicato, cujo mandato foi de 2012 a 2016, e outro agricultor que se inseriu a partir do trabalho no sindicato como assessor de um deputado federal. 
mento político e a propagação da agroecologia foram processos que se enraizaram nas redes sociais. As redes se tornaram, assim, complexos mecanismos de governança, um substrato fértil ao crescimento das organizações locais e ao acesso a políticas públicas.

A importância de trazer à tona esse elemento singular que revela as bases e os fundamentos das organizações e das redes está ligado à nossa capacidade de compreender a natureza das relações sociais e sua influência no acesso e implementação de políticas públicas. $\mathrm{O}$ acúmulo de experiências com as organizações sociais e com a comercialização via Asimaf foi um ponto positivo que interferiu na venda de produtos para merenda escolar em Espera Feliz. O aprendizado em relação ao processo de venda (gestão da política), ao acesso a políticas públicas e às articulações confere vantagens e autonomia à Coofeliz.

No caso de Guaraciaba, como as associações foram criadas de forma tutelada, basicamente por agentes externos (Emater e prefeitura), e com objetivos voltados ao acesso a programas públicos, elas não desenvolveram habilidades necessárias e nem autonomia relativa para assumirem as rédeas das organizações locais. Pode-se constatar que as organizações são permanentemente travadas por uma espécie de inércia que as empurra a reproduzir as regras do jogo já existentes, definidas por atores mais influentes. Desenraizadas de sua trama social, as associações ficaram dependentes do poder público local para conseguirem vender os produtos para a merenda escolar, uma vez que todo processo burocrático de venda da associação é realizado por um funcionária cedida pela municipalidade local.

De certo, a marginalização da maioria dos agricultores dos processos de operacionalização e acesso aos programas públicos, e mesmo da constituição das associações, ocasiona desconhecimento e afastamento. Ao contrário do que se pensa, a constituição de organizações locais pode não levar à cooperação. Quando o processo de interação não é intensificado pela dinâmica associativa, e esta se torna apenas mera formalidade para acessar recursos, o capital social não é suficiente para produzir ação coletiva e superar as restrições locais do contexto.

A grande questão e o diferencial das organizações é a forma de vínculo criado com o grupo e com a organização. No caso de Espera Feliz, os vínculos dos agricultores com as organizações estão relaciona- dos à construção de uma identidade e à história de um grupo. Criaram vínculos intra e extragrupo. A grande maioria assumiu que não se vinculou a Coofeliz apenas para acessar políticas públicas, apesar de ser um precedente. A relação com o sindicato, a relação com a agroecologia e a importância dada ao processo de cooperação são elementos que definem os vínculos.

Essas constatações indicam que a forma como as organizações foram constituídas e sua trajetória permitem visualizar o seu enraizamento nas estruturas sociais locais. A forma como está definido este enraizamento determina a atuação das organizações. O enraizamento das organizações coletivas vai implicar também no modo como as redes sociais são utilizadas como um capital social derivado das conexões internas e externas ao grupo de agricultores.

Quanto maior o enraizamento da organização nas redes, maior a capacidade de mobilizar as conexões das redes para trazer vantagens e informações às organizações. Os elementos intangíveis mobilizados pelas relações (reputação, confiança, solidariedade, proximidade) se configuram como essenciais ao acumulo do capital social, que pode satisfazer as necessidades do grupo. Estes elementos são colocados como vantagens quando se observa o processo de associação e cooperação. A maior influencia dessa trajetória das organizações reside em compreender o seu enraizamento e a forma como ele permite a utilização das conexões como vantagens (capital social) a ser utilizado no processo associativo.

\section{Conclusões}

Este trabalho ressalta a importância da trajetória das organizações locais e de seu enraizamento nas estruturas sociais para a compreensão da forma como diferentes atores se relacionam e acessam políticas públicas. Não há uma polarização nos casos desta pesquisa de modo que um demostre uma experiência positiva ou ideal, e outro, uma realidade negativa; embora se descreva a construção de lastros de solidariedade e ação coletiva em um e os vínculos instrumentais em outro. A questão em jogo é ponderar que qualquer análise de política pública implementada ao público da agricultura familiar e que leve em consideração as organizações locais precisa se atentar à forma como os atores estão envolvidos e o processo sócio-histórico 
que deu origem a esta realidade, distinguindo a organização como verbo e como substantivo.

Logo, a forma como o tecido social se estrutura é uma variável chave para compreender os resultados locais da nova geração de políticas para a agricultura familiar. Desconsiderar a trajetória e a realidade social é perder de vista a principal dimensão de adaptação da política ao contexto local. Devido às trajetórias sociais e ao formato de constituição das organizações, viu-se que os mediadores/parceiros assumiram papéis diferentes nos casos analisados, o poder público local adotou a direção da execução das políticas públicas em Guaraciaba e as organizações ampliaram suas redes no caso de Espera Feliz ou continuaram restritas ao âmbito local como em Guaraciaba. Isso quer dizer que a posição dos atores nessa rede leva a diferentes formas de atuação.

Conclui-se, então, que a forma de constituição das organizações de agricultores familiares tem determinação direta na sua forma de funcionamento e no modo como acessam e implementam as políticas públicas. Organizações desenraizadas de uma trama social, meramente jurídicas, podem incorrer em dependência do poder público e de agentes externos para acessar certos programas governamentais, e mesmo para se manterem operativas. Estas constatações reforçam a capacidade de influência das relações sociais nos resultados econômicos.

Os casos apresentados mostraram como as organizações locais têm origem no curso das ações empreendidas pelos atores sociais. Portanto, torna-se possível concluir que o contexto sócio-histórico não é apenas um pano de fundo, mas uma variável essencial na compreensão do comportamento dos atores e dos resultados da interação. Uma das principais conclusões a que este trabalho pôde chegar é que, apesar do grande número de associações rurais em um município, isso não revela a densidade das relações sociais nem traduz as relações de cooperação, pois as organizações podem ser meramente formais e socialmente desenraizadas.

Os casos revelam, ainda, as condições sociais herdadas e seus efeitos diferenciais sobre as organizações coletivas e a forma de acesso a políticas públicas. Se o fato de disporem de conexões sociais era crucial para as associações de Guaraciaba alcançarem objetivos imediatos, constatou-se que elas não foram, em geral, suficientes para se sobreporem às restrições de suas realidades. As instituições que condicionam os com- portamentos dos agricultores familiares e constroem as relações de cooperação e valores, como a solidariedade e a confiança, em Espera Feliz, não se manifestaram da mesma forma que em Guaraciaba, produzindo experiências organizativas diferentes e resultando em formas singulares de relação com as políticas públicas.

Vale reforçar que o caso de Guaraciaba não é uma experiência negativa. Apenas traduz uma realidade social. Não quer dizer que as associações estão destinadas a assumirem sempre um papel marginal na condução das políticas públicas por estarem dependentes de sua trajetória. A grande questão é que os valores, os costumes as relações sociais precisarão mudar, ou seja, trata-se em falar de uma lenta e gradual mudança institucional que começa com a reflexão e conscientização dos agricultores sobre os papéis que assumem.

As diferentes configurações das relações interorganizacionais assumidas por Espera Feliz e por Guaraciaba refletem nos recursos acessados por esses grupos de agricultores, bem como no conjunto de políticas e programas governamentais que eles tendem a operar. Assim, os recursos locais herdados podem ser propulsores de novas formas de organização, ou mesmo de reconfiguração das formas existentes, e levar à ampliação dos contatos para fora do âmbito municipal. As redes se diferenciam de acordo com as condições do contexto e lidam de forma diferente com as questões contextuais. Por isso, a forma de operacionalização dos programas estatais e mesmo das relações com atores estatais tomam proporções diferentes nos casos analisados.

\section{Referências}

ABREU, K. D. R. A implementação do Programa Nacional de Alimentação Escolar (PNAE) em municipios de pequeno porte: implicações práticas e teóricas. 2014. 183f. Dissertação (Mestrado Administração pública e Governo) - Fundação Getúlio Vargas, São Paulo.

ASSAO, T. Y. Alimentação escolar: percepções de atores sociais de uma escola da região metropolitana de São Paulo, 2012, 117p. Tese (Doutorado Saúde Pública) - Programa de Pós-graduação em Saúde Pública, Universidade de São Paulo, São Paulo.

BARDIN, L. Análise de conteúdo. Lisboa: Edições Setenta, 2011.

BERMAN, P. El estudio de la macro y microimplementación. In: VILLANUEVA, L. F. A. La 
implementación de las politicas. México: Miguel Ángel Porrúa, 2007. p. 281-317.

BOLTER, J. A. G. Interfaces e cogestão nas politicas para agricultura familiar: uma análise do programa nacional de habitação rural. 2013. 173 f. Tese (Doutorado em Desenvolvimento Rural) - Programa de pós-graduação em Desenvolvimento rural, Universidade Federal do Rio Grande do Sul, Porto Alegre.

BURT, R. S. Structural holes: the social structure of competition. Cambridge: Harvard University Press, 1992.

CAMPOS, A. P. T. Redes sociais, organizações e políticas públicas: interfaces na agricultura do município de Araponga, Zona da Mata de Minas Gerais. 2014, 195f. Tese (Doutorado em Ciências Sociais em Desenvolvimento, Agricultura e Sociedade) Universidade Federal Rural do Rio de Janeiro, Rio de Janeiro.

; MENDES, F. F. Redes sociais, comunidades eclesiais de base e sindicalismo rural: a experiência da conquista de terras em conjunto entre agricultores familiares da Zona da Mata mineira. Revista Ruris, Campinas, v. 5, n. 2, p. 15-43, 2011.

CINTRÃO, R. P. ONGs, tecnologias alternativas $e$ a representação politica do campesinato: uma análise da relação do centro de tecnologias alternativas e os sindicatos de trabalhadores rurais na Zona da Mata mineira. 1996. 209f. Dissertação (Mestrado em Ciências Sociais em Desenvolvimento, Agricultura e Sociedade) - Universidade Federal Rural do Rio de Janeiro-CPDA, Rio de Janeiro.

COLEMAN, J. S. Foundations of social theory. Cambridge: Harvard University Press, 1990.

COMERFORD, J. C. Como uma família: sociabilidade, territórios de parentesco e sindicalismo rural. Rio de Janeiro: Relume Dumará: Núcleo de Antropologia da Política/UFRJ, 2003.

COSTA, J. M. N. Política de alimentação escolar: tem caroço nesse angu? A gestão e o controle social do PNAE. 2013. 185f. Dissertação (Mestrado profissional em educação) - Universidade de Brasília, Brasília-DF.

CUNHA, W. A. Implicações dos programas governamentais de aquisição de alimentos para a agricultura familiar em Espera Feliz-MG. 2015, 164f. Dissertação (Mestrado em Administração) - Universidade Federal de Viçosa Minas Gerais.

FREITAS, A. F.; FREITAS, A. F. Os alicerces sociopolíticos do cooperativismo de crédito rural solidário na Zona da
Mata de Minas Gerais. Revista de Economia e Sociologia Rural, Brasília, v. 51, p. 433-453, 2013.

FRIEDLAND, R.; ALFORD, R. R. Introducendo de nuevo a La sociedad: símbolos, prácticas y contradiciones institucionales. In: POWELL, W. W.; DIMAGGIO, P. J. (Orgs.). El nuevo institucionalismo em el análisis organizacional. Trad.: Roberto Ramón Reyes Mazzoni. México: Fondo de Cultura Económica, 1999. p. 294-329.

FROEHLICH, E. A Capacidade de "Fazer Diferente": os condicionantes legais e as estratégias de governança na implementação do programa de alimentação escolar em Dois Irmãos e Tapes (RS). 2010, 152f. Dissertação (Mestrado em Desenvolvimento Rural) - Faculdade de ciências econômicas da Universidade Federal do Rio Grande do Sul, Porto Alegre.

GAMBETTA, D. Trust: making and breaking cooperative relations. Oxford: Basil Blackwell, 1988.

GRANOVETTER, M. The strength of weak ties. American Journal of Sociology, Chicaco, v. 78, n. 6, p. 13601380, 1973.

. The impact of social structure on economic outcomes. Journal of Economic Perspectives, Chicaco, v. 19, n. 1, p. 33-50, 2005.

GRISA, C.; SCHNEIDER, S. Três gerações de políticas públicas para a agricultura familiar e formas de interação entre sociedade e estado no Brasil. Revista de Economia e Sociologia Rural, Brasília, v. 52, p. 125-146, 2014.

HOUTZAGER, P. P. Os últimos cidadãos, conflito $e$ modernização no Brasil rural (1964-1995). São Paulo: Globo, 2004.

JANUÁRIO, B. L. A implementação da Lei 11.947/2009 da compra direta da agricultura familiar pelo Programa Nacional de Alimentação Escolar em municípios do estado de São Paulo: possíveis fatores relacionados. 2013, $135 \mathrm{f}$. Dissertação (Mestrado em Saúde Pública). São Paulo: Faculdade de Saúde Pública da USP, 2013.

LIN, N. Social capital - a theory of social structure and action. Cambridge: Cambridge University Press, 2001.

LIPSKY, M. Street-level bureaucracy: dilemmas of the individual in public service. New York: Russell Sage Foundation, 1980.

LONG, N.; PLOEG, J. D. Heterogeneity, actor and structure: towards a reconstitution of the concept of structure. In: BOOTH, D. (Org.). Rethinking social development: theory, research and practice. Essex: Longman Scientific and Technical, 1994, p. 62-89. 
LOTTA, G. O papel das burocracias do nível de rua na implementação de políticas públicas: entre o controle e a discricionariedade. In: FARIA, C. A. P. (Org.). Implementação de políticas públicas: teoria e prática. Belo Horizonte: PUC MG, 2012, p. 20-49.

MANESCHY, M. C.; KLAVDAHL, A. Redes de associações de grupos camponeses na Amazônia Oriental (Brasil): fontes de capital social? REDESRevista Hispana para el Análisis de Redes Sociales, Madrid, v. 12, n. 4, p. 5-19, jun. 2007.

MIZRUCHI, M. S. Análise de redes sociais: avanços recentes e controvérsias atuais. RAE - Revista de Administração de Empresas, São Paulo, v. 46, n. 3, p. 72-86, 2006.

MOSSMANN, M. P. et al. Interface Between Family farmin and school feeding: barriers and coping mechanisms from the perspective os diferente social actors in Southern Brazil. Revista SOBER, Brasília, v. 55, n. 2, p 325-342, 2017.

NORONHA, A P. O acesso dos agricultores familiares prioritários ao Programa Nacional de Alimentação Escolar (PNAE): o caso do município de Capão do Leão, RS. 2013, 170f. Dissertação (Mestrado em Sistemas de produção agrícola familiar) - Universidade Federal de Pelotas, Pelotas, 2013.

PETRINI, J. C. CEBs: um novo sujeito popular. Rio de Janeiro: Paz e Terra, 1984.

PORTUGAL, S. Contributos para uma discussão do conceito de rede na teoria sociológica. Oficina do CES, № 271, 2007. Disponível em: <http://www.ces.uc.pt/publicacoes/ oficina/ficheiros/271.pdf> Acesso em: 21 jan. 2014.

PUTNAM, R. D. Comunidade e democracia: a experiência da Itália moderna. 3. ed. Rio de Janeiro: FGV, 2002.

RIZZA, R. The relationship between economics and sociology: the contribution of economic sociology, setting out from the problem of embeddedness. International Review of Sociology, Chicaco, v. 16, n. 1, p. 31-48, 2006.

SABOURIN, E. Organizações formais e dispositivos coletivos dos agricultores no Nordeste Semi-árido. In:
SABOURIN, E. (Org.). Associativismo, cooperativismo e economia solidária no meio rural. Brasília: Cadernos do CEAM, n. 23, p. 51-93, 2006.

SILVA, M. G. Políticas Públicas de desenvolvimento rural e organizações da agricultura familiar em Espera Feliz. 2010, 127f. Dissertação (Mestrado em Extensão Rural) Universidade Federal de Viçosa, Viçosa.

; AMORIM JUNIOR, P. C. G. Inovações organizacionais para a construção de mercados locais e solidários em Espera Feliz (MG). Revista Agriculturas, Rio de Janeiro, v. 10, n. 5, p. 14-17, 2013.

SILVA, M. K.; SCHMITT, C. J. As organizações sociais e o Programa de Aquisição de Alimentos no Rio Grande do Sul. In: MARX, V. (Org.). Democracia participativa, sociedade civil e território. Porto Alegre: UFRGS/CEGOV, 2014.

SILVA, D. W. Produzindo prerrogativas de cidadania: o acesso da agricultura familiar à política de fornecimento de produtos para a alimentação escolar. 2015, 217f. Tese (Doutorado em Desenvolvimento Rural) Universidade Federal do Rio Grande do Sul, 2015.

STAKE, R. E. The art of case study research. Thousand Oaks, CA: Sage Publications, 1995.

TILLY, C.; GOODIN, R. E. It depends. In: GOODIN, R. E.; TILLY, C. (Eds.). The Oxford handbook of contextual political analysis. Oxford: Oxford University Press, 2006.

TRICHES, R. M.; GRISA, C. Entre mudanças e conservadorismos: uma análise dos programas de aquisição de alimentos (PAA e PNAE) a partir da retórica da intransigência. Revista NERA (UNESP), São Paulo, v. 18, p. 10-27, 2015.

WOOLCOCK, M. Social capital and economic development: toward a theoretical synthesis and policy framework. Theory and Society, Davis, v. 27, n. 2, p. 151-208, 1998.

; NARAYAN, D. Social Capital: implications for development theory, research, and policy. The World Bank Research Observer, Oxford, v. 15, n. 2, p. 22-49, 2000.

Todo o conteúdo deste periódico, exceto onde estiver identificado, está licenciado sob uma Licença Creative Commons (cc by 4.0). 
